\title{
Modelling on Stock Investment Valuation for Long-term Strategy
}

\author{
Shamsul Rijal Muhammad Sabri, Wajeeh Mustafa Sarsour
}

School of Mathematical Sciences, Universiti Sains Malaysia, Penang, Malaysia

Email address:

rijal@usm.my (S. R. M. Sabri),wajeeh.sa88@gmail.com (W. M. Sarsour)

\section{To cite this article:}

Shamsul Rijal Muhammad Sabri, Wajeeh Mustafa Sarsour. Modelling on Stock Investment Valuation for Long-term Strategy. Journal of Investment and Management. Vol. 8, No. 3, 2019, pp. 60-66. doi: 10.11648/j.jim.20190803.11

Received: July 11, 2019; Accepted: August 7, 2019; Published: August 23, 2019

\begin{abstract}
This paper developed long-term investment of stock cash flow activities comprising of how yearly investment contribution turns to share units and vice versa, how the series of dividends pay out are declared and finally, how the growth of share units are generated over the years of investing period. These investment model activities form cash inflows and outflows and hence, in return, the performance of this investment model can be evaluated. In addition, this model also constrained that, the yearly dividends obtained were being reinvested together with the annual contributions in accumulating shares. Besides presenting the computation of purchasing and selling of share units and the amount of dividend obtained, this paper contributed in the computation of the growth of the shares in a year, based on share issuance such as share split or consolidation, as well as bonus share rewards. Based on these activities, the net present value (NPV) was derived and the modified internal rate of return (MIRR) was determined by setting up zero-valued of NPV. We illustrated the computation of MIRR by looking at the investment activity towards Prolexus Berhad from the year 2011 to 2015 . The increasing of company share prices through years, the encouraging series of dividend rates and generous of the company in issuing shares to the shareholders, were also clearly figured that determined attractive MIRR.
\end{abstract}

Keywords: Modified Internal Rate of Return (MIRR), Investment Models, Net Present Value (NPV), Share Split, Bonus Issue

\section{Introduction}

One of the purposes of investing in stock is the ownership of the company invested. The investor's ownership of the company is usually described in terms of the amount of shares hold. The value of his investment is then evaluated by the product of the share units hold and the current stock price. In general, stock prices fluctuation is considered as a promoter in recognizing market performance and have significant role in developing and enhancing the economy. Investors make assessment of listed shares behavior in order to facilitate their investment decisions and to maximize their investment profit. Nevertheless, the investor's earning; to some extent, depend on other market variables, such as market prices volatilities, political instability, and economic performance. However, investors having an outstanding knowledge of financial management, usually make a wise investment decision. Therefore, investors might use different models in choosing their stocks as well as monitoring the performance of their stock portfolios. Stock valuation is one of the investment models, and is defined as a technique where the value of company can be determined, which may inform the investors about the restrictions of the profitability of the company [1].

Recently, several investment models have been proposed to evaluate the stock investment for a certain company. The investment valuations by using net present value (NPV) and internal rate of return (IRR) represent the traditional techniques for stock investment valuation [2-4]. However, different shortcoming and limitations of the NPV and IRR models have been extensively discussed in the literatures [2, $3,5,6]$. One of the main shortcomings of these models is the implementation of IRR computation in which a single investment project may have multiple values of IRR [2, 7, 8, 9]. In order to overcome this issue, scholars firstly pioneered the modified internal rate of return (MIRR) during the 18th century and rediscovered it later in 1950s. This model assumes reinvestment of cash inflows at the reinvestment rate 
and does account for the periodic free cash flows [2, 10, 11]. Hence, MIRR solves the problem of multiple values of IRR. The MIRR here is defined as the rate at which the NPV equals zero where the present value of terminal value of the invested fund at the end equals to the present value of the series of annual contributions over the investment period [12].

A number of studies indicate that MIRR is better than IRR models in which the discounted cash flow (DCF) analysis is recalibrated to reveal more predictable NPV [2, 3, 13, 14]. Kovvali (2009) evaluated different investment projects using the MIRR and MIRR adjusted for time scale approaches utilizing data for four Indian watersheds [3]. Lifland (2015) revealed a more predictable NPV by facilitating the DCF analysis using the MIRR model [13]. Furthermore, Erményi (2015) showed that when the amount reinvested is lower than the IRR, the rate of return of an investment would be overestimated by IRR [14]. However, the study recommended using the MIRR since it considers the cost of capital and thus providing more effective investment evaluation. Despite these advantages of the MIRR model, it is not widely used in the literature [15].

Even though the above-mentioned studies have shown that the adoption of MIRR as a tool of stock investment valuation being considered as the best choice, it did not take into considerations the issuance of shares such as split and bonus issues in calculating MIRR. In accordance with the issuance function, share splits can be defined as the process of increasing the number of outstanding shares for a certain company without affecting the equity of shareholders, while the bonus share is defined as the process of increasing the number of outstanding shares by offering free extra shares to the shareholders in which their wealth remains the same [16]. Moreover, bonus shares issuance will not cost the company [12]. The share's issuance such as share split and bonus may have several effects on the stock prices, number of outstanding shares and market efficiency during the investment year. These effects may cause abnormal returns, which may happen at random and positively affect the stock prices [17-23].

On a theoretical basis, however, investors do not consider the share issuance in their investment, which does not affect the wealth of shareholders [17, 24]. When the company practices share issuance such as splitting shares, the investor's capital remains the same even though his ownership increases as of multiplication of share units. This is because of the share split declines stock prices provided the non-payment of dividend distributed in a particular year $[17,25,26]$. On the other hand, the bonus issue might assist the shareholders in conserving their stocks on the company and it might provide a sign for higher investment profit in the future in which managers do issue bonus shares in case they have a positive indication about the future profit [17, 27].

This paper seeks to develop long-term investment framework comprising of annuity series of cash investments contributed together with a series of dividends earned and the terminal investment fund sold at the end of the period. In this strategy, the dividends are reinvested together with the investment contributions every beginning of the year. Furthermore, other share issuances such as share split or reverse split and bonus share issue are included in the model, which makes our adoption of MIRR computation is crucial in stock valuation. Section 2 provides investment methodology in projecting the cash inflows and outflows together with the changes in outstanding share units. This section also defines the NPV for long-term investment model. In addition, by the assistance of software computation (in this case, we incorporated the Microsoft Excel), the calculation of MIRR is more likely improving and the long term stock investment valuation is accurate since it is based on different factors such as stocks price and dividend simultaneously other than the previous methods. Section 3 illustrates the investment model with the given Prolexus Berhad company case in determining the MIRR for a 5-year period. Section 4 concludes the overall contributions.

\section{Stock Investment Cash Flow, NPV and MIRR}

One of the main objectives of stock valuation is to determine which of the stocks studied are profitable to be invested. In this paper, the profitable key here is the internal rate of return (IRR), in which the higher return brings more profitable investment. In long term investment, the rate of return is not simply defined by the ratio function of two stock prices. Therefore, an investment strategy guideline must be clearly underlined.

The objective of the long term strategy is to increase the investor's ownership of a certain company in a determined period of investment. By this strategy, the investor will be committed in contributing a certain amount annually in advanced to earn the share units of the company. His/her share capital will also be increased by reinvesting the annual dividends declared by the company. If the company held consistently makes profit, it will generously award share bonus that consequently increases the ownership of the investor. For long term investment strategy,

a. advanced series of level contributions, $C$ s are allocated in purchasing share units of a particular stock for $T$ years. Therefore, amount of $T C$ is committed over the period of investment. This is practical for retail investors and many financial institutions such as mutual trusts, insurance industries, pension schemes and many more.

b. the yearly dividend earned, if the dividend per share (dps) declared, is reinvested on the same stock. This indicates how committed the investor towards the stock he/she has chosen.

c. as the investor believes that the stock held is profitable in the future, no withdrawal made during the investment period.

d. share units purchased will be experiencing share issuance such as share split/consolidation and bonus 
issue. Other than these issues such as right issue and share buyback/treasury shares are not considered into this investment model.

e. at the end of $T$ years, all share units are sold to determine the profit or loss of the investment. The total shares sold together with the final dividend and balance that are not invested, is called as terminal fund.

Let a discrete yearly time series be defined as, $t=$ $1,2, \ldots, T$ where $T$ is an investment year period. We may also define $u_{t, 1}$ and $u_{t, 2}$ as the respective dates in year $t$, which are the purchasing of share units made at the beginning and the yearly financial report released on year $t$. Here, we notice that, $u_{t, 1}<u_{t, 2} \leq u_{t+1,1}$.

At the beginning of year $t$, an amount of $C$ is initially allocated to purchase $E_{t}$ share units. Bursa Malaysia regulates the investors to trade stocks in board lot. This means the investor is entitled to buy or sell his/her stocks in amount of lots only where, 1-lot stock according to the Bursa Malaysia rules is determined to be equivalent to 100 share units. Hence, by assuming zero charge of brokerage fees, the share units bought, $E_{t}$ and the exact contribution, $C_{t}$ are defined as,

$$
E_{t}=\operatorname{Int}\left(\frac{C+B_{t-1}+D I V_{t-1}}{100 \times P_{u_{t, 1}}}\right) \times 100
$$

and,

$$
C_{t}=E_{t} \times P_{u_{t, 1}}
$$

where, $P_{u_{t, 1}}$ is the share price on date $u_{t, 1}$, and $B_{t-1}$ and $D I V_{t-1}$ are the balance after contribution of $C$ is made and amount of dividend rewarded in the previous year, respectively. Here, we may simplify $B_{t}=D I V_{t-1}+C-C_{t}$. This balance will be used to invest together with yearly contribution, $C$ and dividend earned, $D I V_{t}$ for the next year. Thus, for $t=1$, the respective initial amount of share units purchased and exact amount of investment are defined as,

$$
E_{1}=\operatorname{Int}\left(\frac{C}{100 \times P_{u_{1,1}}}\right) \times 100 \text { and } C_{1}=E_{1} \times P_{u_{1,1}}
$$

For the first year, we may also define the accumulated share units on date $u_{1,1}$ as, $S_{1}^{(1)}=E_{1}$. During the year of investment period, the company may issue an increment/decrement of share units that reflects on significant changes to the shares hold by the investors such as share split/consolidation, which is denoted as $S p l$, and bonus

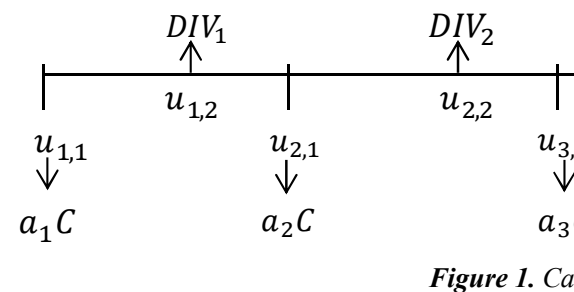

Figure 1. Cashfow of stock investment.

Figure 1 illustrates the procedure of the cash flows of stock investment over $T$ years. These investment procedures are repeated until at year $T$, where the balance, $B_{T}$ and the dividend earned, $D I V_{T}$ are no longer reinvested. For $t=$
(Bns) issuance. The issues are assumed to happen at time $u_{t, 2}$ and the issuance function is defined as $g$. Thus, the new accumulated shares after issuance at time $u_{t, 2}$ is,

$$
S_{t}^{(2)}=g_{t}\left(S p l_{t}, B n s_{t}\right) \times S_{t}^{(1)},
$$

and, we may define $g_{t}$ as,

$$
g_{t}\left(S p l_{t}, B n s_{t}\right)=\left(1+B n s_{t}\right) \times S p l_{t} .
$$

It should be noticed that, when split or consolidation of shares is not happening on a particular year, then $S p l=1$. For example, in a financial report of year $t$, the directors of a company issue a bonus on the basis of one (1) share for every two (2) existing ordinary shares. In addition, they also announce share split involving the subdivision of every one (1) existing ordinary share into five (5) new ordinary shares. This results in $B n s_{t}=1 / 2$ and $S p l_{t}=5,[15,16]$, and thus giving $g_{t}(5,1 / 2)=(1+1 / 2) \times 5=7.5$. If $S_{t}^{(1)}=15,000$, then by incorporating equation (3), the current share units after the share issuance grow to $S_{t}^{(2)}=7.5 \times 15,000=$ 112,500 .

The next accumulated shares, $S_{t+1}^{(1)}$ are then being the total of the previous share units after share issuance and the current share units purchased and recursively be determined as,

$$
S_{t+1}^{(1)}=S_{t}^{(2)}+E_{t+1}
$$

If the company is declaring dividend, assumed that the dividend distributed is on the date of the financial year report published, $u_{t, 2}$. With the defined dividend per share, $d_{t}$, the amount of dividend, $D I V_{t}$ is partitioned by two components; the dividend obtained from the existing share units, $D I V_{t}^{(1)}$ and the dividend earned from the new purchased share units, $D I V_{t}^{(2)}$. A noticeable $D I V_{t}^{(1)}$ is computed as $D I V_{t}^{(1)}=S_{t-1}^{(2)} \times$ $d_{t}$ [28]. If the period from $u_{t, 1}$ to $u_{t, 2}$ is less than one year, we may apply prorate amount of dividend payment, $D I V_{t}^{(2)}$. Hence, the linear approximate of dividend payment $D I V_{t}^{(2)}$ is suggested as,

$$
D I V_{t}^{(2)}=\left(\frac{u_{t, 2}-u_{t, 1}}{365}\right) \times E_{t} \times d_{t}
$$

Finally, the total dividend, $D I V_{t}$ is determined as,

$$
D I V_{t}=D I V_{t}^{(1)}+D I V_{t}^{(2)}=\left[S_{t-1}^{(2)}+\left(\frac{u_{t, 2}-u_{t, 1}}{365}\right) E_{t}\right] d_{t} .
$$

$2, \ldots, T$, the general formulation can be derived recursively to obtain the accumulated share units $S^{(1)}$ and $S^{(2)}$, and dividend payment $D I V_{t}$, as follows, 


$$
\begin{gathered}
S_{t}^{(1)}=\sum_{w=1}^{t-1} E_{w}\left(\prod_{v=w}^{t-1} g_{v}\right)+E_{t} \\
S_{t}^{(2)}=\sum_{w=1}^{t} E_{w}\left(\prod_{v=w}^{t} g_{v}\right), \text { and } \\
D I V_{t}=D I V_{t}^{(1)}+D I V_{t}^{(2)}= \\
{\left[\left(\frac{u_{t, 2}-u_{t, 1}}{365}\right) E_{t}+\sum_{w=1}^{t-1} E_{w}\left(\prod_{v=w}^{t-1} g_{v}\right)\right] d_{t}}
\end{gathered}
$$

The accumulated share units, $S_{T}^{(2)}$ are then sold at time $u_{T+1,1}$. The terminal value of invested fund, $F(T)$ is defined as $F(T)=S_{T}^{(2)} \times P_{u_{T+1,2}}+B_{T}+D I V_{T}$, where, $P_{u_{T+1,1}}$ is the share price sold at time $u_{T+1,1}$. By incorporating equations (8) and (9), the terminal value of invested fund can be derived as,

$$
F(T)=\sum_{w=1}^{T} E_{w}\left(\prod_{v=w}^{T} g_{v}\right) \times P_{u_{T+1,1}}+B_{T}+\left[\left(\frac{u_{T, 2}-u_{T, 1}}{365}\right) E_{T}+\sum_{w=1}^{T-1} E_{w}\left(\prod_{v=w}^{T-1} g_{v}\right)\right] d_{T}
$$

Given $C=\left(C_{1}, \ldots, C_{T}\right)^{\prime}, \quad d=\left(d_{1}, \ldots, d_{T}\right)^{\prime}, \quad P=$ $\left(P_{u_{1,1}}, \ldots, P_{u_{T, 1}}, P_{u_{T+1,1}}\right)^{\prime}$ and $g=\left(g_{1}, \ldots, g_{T}\right)^{\prime}, F(T)$ forms the function $F(T) \equiv F(T, C, d, P, g)$, which is more complicated to be derived recursively. Sometimes, there can be a year where we couldn't afford to purchase the share due to high price of a share unit. Hence, we delay our trading to the next year and double our contribution in the hope to be sufficient to purchase our minimum lot of unit shares next year. For instance, supposed that our annual contribution is $C=\mathrm{RM} 1,000$. If the share price in the date $u_{t, 1}$ for stock A is RM15, we are lack of RM500 to earn a lot of stock A (by assumption of no trading fees imposed and the board lot is 100 share units per lot). Hence, $C_{t}^{*}=0$ and we may delay our investment and accumulate our contribution up to RM2,000 (i.e. $C_{t+1}^{*}=2 \times R M 1000$ ). If the share price for the next year remains the same, or increases, but not more than RM20 per share, our next contribution is sufficient to purchase stock A. Mathematically, $C_{t}^{*}$ can be set to zero, a unit of $C$, or a product of an integer, $a_{t}$ with $C$, subject to $\sum_{t=1}^{T+1} C_{t}^{*}=T C$. In our stock valuation, we may define our annual contribution as $C_{t}^{*}=a_{t} C$, where $a_{t}$ is defined as an integer such that, $\sum_{t=1}^{T+1} a_{t}=T$. Hence, if all contributions have been allocated, then $a_{T+1}=0$. Figure 1 illustrates the series of cash outflows comprising of the integers $a_{t}$.

The computation of $F(T)$ is held by few assumptions:-

a. All contributions are being invested every beginning of the year. Hence, the yearly contributions can be computed and is determined as $C_{t}^{*}$, where, $t=$ $1,2, \ldots, T+1$ (see figure 1$)$.

b. The financial report published every once in calendar year basis. If the company skips one year report, then the dividend remains zero and the share issuance function, $g$ is set to be 1 . If there are two reports within one year, we take the recent report in determining the share units based on share issuance announced, and the dividend rate is set based on sum of rate from the previous and recent on that year.

The NPV is defined as the difference of the present value between cash inflows and cash outflows. Cash inflows are determined by the series of dividends awarded and the terminal value of the invested fund at the end of $T$ years, $F(T)$ whereas money outflows are determined by the series of yearly contributions over $T$ years, $C^{*}$. By assuming the level rate of yearly return, $r$ for all years, the NPV can be initially derived as,

$$
\begin{aligned}
N P V & =F(T)(1+r)^{-\frac{u_{T+1,1}-u_{1,1}}{365}}-\sum_{t=1}^{T+1} C_{t}^{*}(1+r)^{-\frac{u_{t, 1}-u_{1,1}}{365}} \\
& =\left[S_{T}^{(2)} P_{u_{T+1,2}}+B_{T}+D I V_{T}\right](1+r)^{-\frac{u_{T+1,1}-u_{1,1}}{365}}-C \sum_{t=1}^{T+1} a_{t}(1+r)^{-\frac{u_{t, 1}-u_{1,1}}{365}} .
\end{aligned}
$$

From equation (11), $r$ is called modified internal rate of return, i.e., $r=$ MIRR when NPV $=0$ [29]. Since the following obstacles occur,

a. amount of dividend declared may vary throughout years,

b. the occurrence of share issuance (split, consolidation and bonus), and

c. purchasing of stock's share units involves the uncertainty of stock price movement and the purchasing of share units is made up by lots only - thus reflecting to the yearly invested $C^{*}$ s becoming not level over the years,

the MIRR could not simply be obtained using equation (11). As it is too tedious to derive the function of $F(T)$, the assistance of software computation such as the Microsoft Excel is required. In this procedure, we compute the respective present values of cash inflows and outflows. Based on the least value of $r$ (say $r=-0.9$ ), we may initially get the NPV is far away positive. Then, we may use the "Goal Seek" function from the Microsoft Excel software that can be obtained from the "What-If Analysis" function. Via this function, we set the NPV value as zero to search for value of $r$. This suggests an appropriate determination value of $r$ becomes MIRR.

\section{Illustration of MIRR Computation}

We illustrate the computation of stock investment cash flows, NPV, and the determination of MIRR by looking at Prolexus Berhad (i.e., stock code being 8966), a Malaysian public listed consumer product company from year 2011 to 2015. Briefly, the company headquarter is located in Kluang, Johore in the west Peninsular of Malaysia. Its core business is more on apparel and textile manufacturing. It has worked with top sports and fashion brands such as Nike, Converse, Under Armour, Disney and GAP. For the past recent years, the company's market capitalization has been increased due to significant issues of share that reflects to the growth of 
shareholders' ownership such as subdivision share and bonus issue. From the year 2011 to 2015, the amount of the company's equity increased from RM53,279,000 to RM126,129,000 yielding 18.8\% growth per annum. The dividend rates (in RM), and share issuance announcement (share split and bonus issuance) can be obtained from the Prolexus Berhad annual report published which can be downloaded from the Bursa Malaysia website. The company's share prices are obtained from the Wall Street Journal website.

By this investment strategy, we allocate RM10,000 every beginning of the year for five-year period from $3 / 1 / 2011$ to $3 / 1 / 2015$, and withdraw our investment fund on $31 / 12 / 2015$. The investment information from 2011 to 2015 for Prolexus Berhad is summarized in Table 1.

Table 1. Investment information of Prolexus Berhad from 3/1/2011 to 31/12/2015.

\begin{tabular}{|c|c|c|c|c|c|c|c|c|}
\hline \multirow{2}{*}{$t$} & \multicolumn{2}{|l|}{ Date } & \multicolumn{2}{|c|}{ Share Price } & \multirow{2}{*}{$d_{t}(\mathrm{RM})$} & \multirow{2}{*}{$S p l_{t}$} & \multirow{2}{*}{ Bns $_{t}$} & \multirow[b]{2}{*}{$g_{t}$} \\
\hline & $u_{t, 1}$ & $u_{t, 2}$ & $P_{u_{t, 1}}$ & $P_{u_{t+1,1}}$ & & & & \\
\hline 1 & $3 / 1 / 2011$ & $31 / 7 / 2011$ & 0.107 & 0.114 & 0.00 & 1 & 0 & 1 \\
\hline 2 & $3 / 1 / 2012$ & $31 / 7 / 2012$ & 0.114 & 0.274 & 0.03 & 1 & 0 & 1 \\
\hline 3 & $3 / 1 / 2013$ & $31 / 7 / 2013$ & 0.282 & 0.646 & 0.03 & 1 & 0 & 1 \\
\hline 4 & $3 / 1 / 2014$ & $31 / 7 / 2014$ & 0.640 & 0.988 & 0.03 & 2 & 0 & 2 \\
\hline 5 & $3 / 1 / 2015$ & $31 / 7 / 2015$ & 0.979 & 2.125 & 0.05 & 1 & 0.4 & 1.4 \\
\hline
\end{tabular}

Note: $g_{t}\left(S p l t_{t}, B n s_{t}\right)$ is computed by using equation (4) from the given information in colums $S p l_{t}$ and $B n s_{t}$.

Over five-year period, Prolexus Berhad issued share split of every one (1) existing ordinary share into two (2) new ordinary shares in the financial year 2014, and also issued bonus share on the basis of two (2) shares for every five (5) existing ordinary shares in the year 2015. By incorporating equation (4), we may obtain, $g_{4}(2,0)=(1+0) \times 2=2$ and $g_{5}(1,2 / 5)=(1+0.4) \times 1=1.4$.

Table 2 illustrates how investment information in Table 1 can be utilized in constructing the investment cash inflows and outflows from the formula given in section 2 .

Table 2. Investment Cashflow in Prolexus Berhad-2011-2015.

\begin{tabular}{lllllll}
\hline $\boldsymbol{t}$ & $\boldsymbol{C}_{\boldsymbol{t}}$ & $\boldsymbol{E}_{\boldsymbol{t}}$ & $\boldsymbol{B}_{\boldsymbol{t}}$ & $\boldsymbol{S}_{\boldsymbol{t}}^{(\mathbf{1})}$ & $\boldsymbol{S}_{\boldsymbol{t}}^{(2)}$ & $\boldsymbol{C}_{\boldsymbol{t}}^{*}$ \\
\hline 1 & $9,993.80$ & 93,400 & 6.20 & 93,400 & 93,400 & 0.00 \\
2 & $9,997.80$ & 87,700 & 8.40 & 181,100 & 181,100 & $4,315.73$ \\
3 & $14,297.40$ & 50,700 & 26.73 & 231,800 & 231,800 & 6,3000 \\
4 & $16,320.00$ & 25,500 & 10.65 & 257,300 & 514,600 & 73 \\
5 & $17,328.30$ & 17,700 & 74.40 & 532,300 & 74,000 & 10,000 \\
\hline
\end{tabular}

From Table 2, the terminal investment fund can be obtained by multiplying $S_{5}^{(2)}$ and stock price on $31 / 12 / 2015$, with summation of the final dividend earned and the small balance of contribution. Hence,

$$
F(5)=745,220 \times \mathrm{RM} 2.125+\mathrm{RM} 25,730.00+\mathrm{RM} 74.40=\mathrm{RM} 1,609,903.65
$$

By using equation (11), and setting $a_{6}=0$, we may obtain the NPV as follows,

$$
N P V=1,609,903.65 \times(1+r)^{-\frac{(31 / 12 / 2015)-(3 / 1 / 2011)}{365}}-10,000 \sum_{t=1}^{5}(1+r)^{-\frac{u_{t, 1}-(3 / 1 / 2011)}{365}}
$$

From the above equation, the MIRR by investing into Prolexus Berhad is calculated as $150.27 \%$ per annum. Although the yearly rate of return for five-year investment period seems too huge, it however makes sense that the increment of stock price, the promising series of dividends payout that have been reinvested, and the share issuance that results in growth of share units, contribute to the share capital arisen and high value of MIRR determined.

Figures 2, 3 and 4 exhibit clear picture on how the investment layouts turn to grow to terminal fund at the end of the year. An exponential increasing of stock price from the beginning of year 2011 to the end of year 2015 as indicated in figure 2, yields $\left(\frac{2.125}{0.107}\right)^{\frac{1}{5}}-1=81.80 \%$ per year.

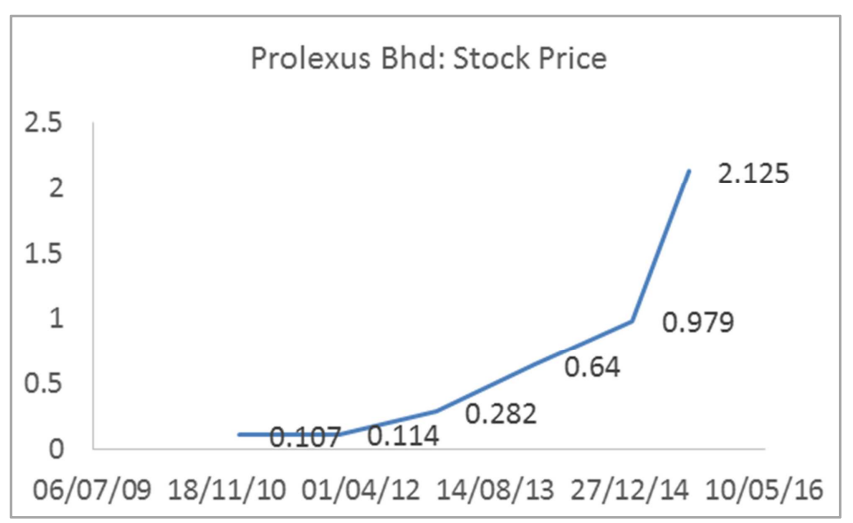

Figure 2. Time series plot of Prolexus Bhd's stock price from 3/11/2011 to $31 / 12 / 2015$. 


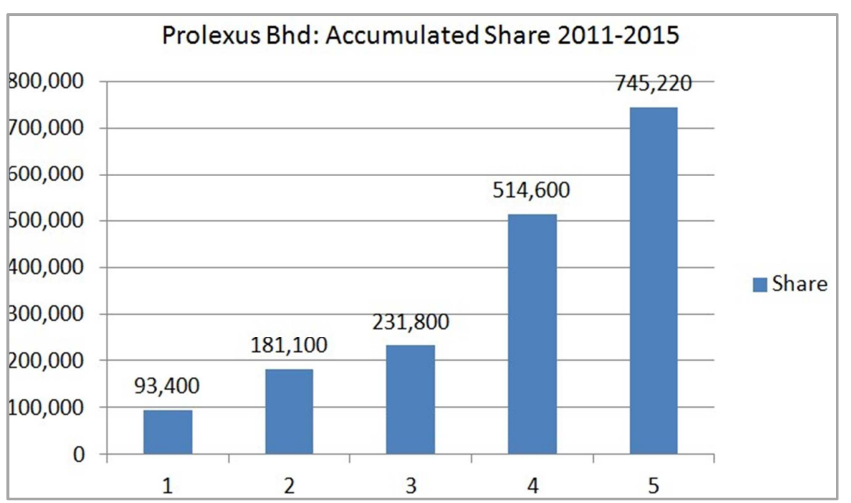

Figure 3. Prolexus Bhd's Accumulated Share from 2011 to 2015 for 5-year duration at $C=R M 10,000$.

In addition, figure 3 illustrates the growth of accumulated share by implying this investment strategy. As can be seen in table 1 and figure 2, the stock prices for the first two years have not changed too much. This yields almost doubled increment of share units (i.e., $181,100-93,400=87,700$ ). For the third year investment, as the share prices hike, we couldn't purchase more share lots as previous even though we use an extra amount dividend of RM4,315.73 as this yields the increment of $231,800-181,100=50,700$ units. However, the company then generously implements share subdivision and bonus share during fourth and fifth year investment. This split issue results in double increment of share units on the fourth year investment. In addition, exceptional dividend payments of RM6,303.93 and RM7,392.04 also contribute to increment of share unit at the end, after bonus issue, i.e. $745,220-514,600=230,620$ units increment.

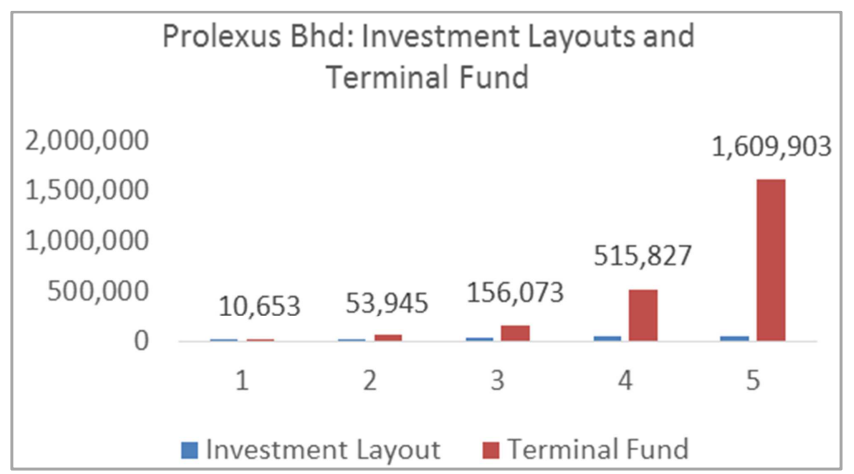

Figure 4. Prolexus Bhd's Investment Layouts and Terminal Fund from 2011 to 2015 for 5-year duration at $C=R M 10,000$.

In figure 4, we compare our investment layouts (in blue color) with the terminal investment fund (in red color) from one to five year investment period. For one-year investment period, our initial layout of RM10,000 is invested in $3 / 1 / 2011$. This fund accumulates to RM10,653.8 (i.e $93,400 \times 0.114+6.20 \quad$ ), attaining $6.59 \% \quad$ yield approximately. If we continuously contribute another RM10,000 for the next year, our investment layouts becomes RM20,000 and our terminal fund, grows to $181,100 \times$ $R M 0.274+R M 8.4+R M 4,315.73=R M 53,945.53$. Then by using equation (11) subject to zero-valued of NPV, the system below,

$$
\begin{gathered}
53,945.53 \times(1+r)^{-\frac{(31 / 12 / 2012)-(3 / 1 / 2011)}{365}-10,000[1} \\
\left.+(1+r)^{-\frac{(3 / 1 / 2012)-(3 / 1 / 2011)}{365}}\right]=0
\end{gathered}
$$

results in increasing of MIRR to $87.98 \%$. By continuously investing to this company, we may extensively obtain the values of MIRRs as 109.48\% (3-year investment), 135.67\% (4-year investment) and $150.27 \%$ (5-year investment). For this stock, the longer period held, the better the MIRR obtained, and hence, our investment capital will increase attractively.

\section{Conclusion}

Previous strategies in assessing the companies' returns on assets and investments, and other financial key ratios determined the potential companies to be owned in the future. However, it does not portray the investor's growth of share asset as the companies' returns from financial key ratios are not necessarily being the indicators of the return on the investment from the shareholders' perspective. For example, if the company return on investment for a particular year is 0.2 , it does not tell us that our share capital invested into that company grows up to $20 \%$ for the next year. Therefore, an exceptionally good procedure must be considered to determine a rate of return that is influenced by the movement of stock price timely, the continuation of dividend payouts that can be potentially reinvested, and the impact of share issuance that increase the amount of shareholder's ownership. In order to assess the rate of return for the long term stock investment, this paper offers such procedure to calculate the desired return.

This paper also contributes to the literature in the following ideas:

a. The simple way of computing the number of share units purchased.

b. The growth of shares over a particular year may be influenced by the share issuance such as share split of reverse split and bonus share award. Hence, an appropriate function of share issuance must be addressed. In this paper, we introduced the share issuance function as in equation (3) and yet a proper computation on this equation needs to be improved.

c. The distribution of dividend is normally based on the rate of dps. Sometimes the date of dividend payout is not documented in the report, therefore the prorate method of dividend payout is incorporated towards the purchased share units as in equation (6).

d. The method of annuity on investing in stock has been widely practiced in a financial institution. Thus, computing the NPV and MIRR are requisite in performing the long-term stock valuation.

In stock investment, there have been several other share issuances that influence positively the existing shareholder's share growth such as awarding extra share units or warrants if 
they purchase the shares more. Some companies may issue share bonus generously to its employees by employees stock and options scheme (ESOS). However, the deal of share issuance happens in a short period of time for a particular year and thus, the shareholder will miss out this opportunity. Hence, by assuming that we are not an employee of the company, we exclude these assumptions to avoid these difficulties.

A 5-year investment valuation of Prolexus Berhad has been illustrated in determining its MIRR. However, if all companies in the consumer product sector here have been gathered in the study, the strength of the Prolexus Berhad return can be observed relatively and the interesting study of MIRR behavior can be proceed extensively.

\section{References}

[1] Besley, S. and Brigham, E. F. (2015). CFIN4 (with Finance CourseMate). (4 Ed), Cram101 Textbook Reviews.

[2] Kierulff, H. (2008). MIRR: A better measure. Business Horizons, 51 (4), 321-329.

[3] Kovvali, S. J. S. (2009). Application of Modified Internal Rate of Return Method for Watershed Evaluation. Agricultural Economics Research Review, 22 (Conference Number), 401406.

[4] Bonazzi, G. and Lotti, M. (2016). Evaluation of Investment in Renovation to Increase the Quality of Buildings: A Specific Discounted Cash Flow (DCF) Approach of Appraisal. Sustainability, 8 (3), 268.

[5] Beaves, R. G. (1988). Net present value and rate of return: Implicit and explicit reinvestment assumptions. The Engineering Economist, 33 (4), 275-302.

[6] Brealey, R. A., Myers, S. C., \& Allen, F. (2006). Principles of corporate finance (8th Ed.). Boston: McGraw-Hill/Irwin.

[7] Wiar, R. C. (1973). Economic implication of multiple rates-of return in the leveraged lease context. The Journal of Finance, 28 (5), 1275-1286.

[8] Hazen, G. B. (2003). A new perspective on multiple internal rates of return. The Engineering Economist, 48 (1), 31-52.

[9] Osborne M. J. (2010). A resolution to the NPV-IRR debate? The Quarterly Review of Economics and Finance, 50, 234239.

[10] Baldwin, R. H. (1959). How to assess investment proposals. Harvard Business Review, 37 (3), 98-104.

[11] Biondi, Y. (2006). The double emergence of the modified internal rate of return: The neglected financial work of Duvillard (1755 - 1832) in a comparative perspective. The European. Journal of the History of Economic Thought, 13 (3), 311-335.

[12] Quiry, P., Dallocchio, M., LeFur, Y., and Salvi, A. (2005). Corporate Finance: Theory and Practice, (6th Ed). John Wiley \& Sons Ltd.

[13] Lifland, S. (2015). A Dynamic Model for the Valuation of a
Capital Investment: The Use of a Monte Carlo Simulation and the Stratification of the Modified Internal Rate of Return Within a European Put Option Strategy. Journal of Accounting and Finance, 15 (7), 64-78

[14] Erményi, S. (2015). Evaluating Investment Profitability and Business Controlling Methods. Management, Enterprise and Benchmarking in the 21st Century, Budapest, Hungary.

[15] Ryan, P. A., \& Ryan, G. P. (2002). Investment practices of the Fortune 1000: How have things changed?. Journal of Business and Management, 8 (4), 355-364.

[16] Ross, A, S., Westerfield, R, W., and Jordan, B, D. (2010). Fundamental of Corporate Finance. The McGraw-Hill Companies, Inc.

[17] Isa, M. M. and Hong, K, T. (1997). The Announcement Effects of Rights and Bonus Issues on Malaysian Stock Prices. Capital Markets Review, 5 (2), 45-58.

[18] Dhar, D. and Ghhaochharia, S. (2008), Market Reaction Around the Stock Splits and Bonus Issues: Some Indian Evidence. Social Science Research Network, available at: http://dx.doi.org/10.2139/ssrn.1087200

[19] Mehndiratta, N. and Gupta, S. (2010). Impact of dividend announcement on stock prices. International Journal of Information Technology and Knowledge Management, 2 (2), 405-410.

[20] Ray, K. K. (2011). Market reaction to bonus issue and stock splits in India: An empirical study. The IUP Journal of Applied Finance, 17 (1), 54-69.

[21] Ghatak, A. (2011). Capital market reaction around the stock splits and bonus issues: Evidence from some Indian IT stocks. Research Journal of Social Science and management, 1 (5), 191-213.

[22] Bhuvaneshwari, D. and Ramya, K. (2014). Impact of stock split announceme26nt on stock prices. International Journal of Management, 5 (3), 36-46.

[23] Alex, D. (2017). Analysis of Market Reaction Around the Bonus Issues in Indian Market. Journal of Economics and Sustainable Development, 8 (1), 28-35.

[24] Murray, D. (1985). Further Evidence on the Liquidity effects of Stock Splits and Stock Dividends. Journal of Financial Research, 8 (1), 59-67.

[25] Lakonishok, J. and Lev, B. (1987), Stock Split and Stock Dividends: Why, Who and When. Journal of finance, 42 (4), 913-932.

[26] Lamoureux, C. G., and Poon, P. (1989). The Market Reaction to Stock Split, Journal of Finance, 42 (5), 1347-1370.

[27] Srividya, V. (1999). The Impact of Bonus and Rights Issues on Stock Returns in India, Ph.D. thesis, Department of Commerce, Bharathiar University, India, http://hdl.handle.net/10603/101682.

[28] Carrel, L., (2010). Dividend Stocks For Dummies. Wiley Publishing, Inc.

[29] Kellison, S, G. (2009). The Theory of Interest. (3rd Ed). McGraw Hill Education. 